\title{
Iron oxide ores as carriers for the production of high purity hydrogen from biogas by steam-iron process
}

\author{
J. Lachén, J. Plou, P. Durán, J. Herguido, J.A. Peña \\ Aragon Institute of Engineering Research (I3A), Universidad Zaragoza, Mariano Esquillor, s/n, Ed. "I+D”, E50.018 \\ Zaragoza, Spain
}

\section{A R T I C L E I N F O}

Article history:

Received 14 October 2016

Received in revised form

21 November 2016

Accepted 24 November 2016

Available online $\mathrm{xxx}$

Keywords:

Iron ore

Biogas

Hydrogen

Purification

Steam iron

Chemical looping

\begin{abstract}
A B S T R A C T
Production of high purity hydrogen ( $<50 \mathrm{ppm} \mathrm{CO}$ ) by steam-iron process (SIP) from a synthetic sweetened biogas has been investigated making use of a natural iron ore containing up to $81 \mathrm{wt} \%$ of hematite $\left(\mathrm{Fe}_{2} \mathrm{O}_{3}\right)$ as oxygen carrier. The presence of a lab-made catalyst ( $\mathrm{NiAl}_{2} \mathrm{O}_{4}$ with $\mathrm{NiO}$ excess above its stoichiometric composition) was required to carry out the significant transformation of mixtures of methane and carbon dioxide in hydrogen and carbon monoxide by methane dry reforming reaction. Three consecutive sub-stages have been identified along the reduction stage that comprise $\mathrm{A}$ ) the combustion of $\mathrm{CH}_{4}$ by lattice oxygen of $\mathrm{NiO}$ and $\mathrm{Fe}_{2} \mathrm{O}_{3}, \mathrm{~B}$ ) catalyzed methane dry reforming and $\mathrm{C}$ ) $\mathrm{G}-\mathrm{G}$ equilibrium described by the Water-Gas-Shift reaction. Oxidation stages were carried out with steam completing the cycle. Oxidation temperature was always kept constant at $500{ }^{\circ} \mathrm{C}$ regardless of the temperature used in the previous reduction to minimize the gasification of eventual carbon deposits formed along the previous reduction stage. The presence of other oxides different from hematite in minor proportions $\left(\mathrm{SiO}_{2}, \mathrm{Al}_{2} \mathrm{O}_{3}, \mathrm{CaO}\right.$ and $\mathrm{MgO}$ to name the most significant) confers it an increased thermal resistance against sintering respecting pure hematite at the expense of slowing down the reduction and oxidation rates. A "tailor made" hematite with additives $\left(\mathrm{Al}_{2} \mathrm{O}_{3}\right.$ and $\left.\mathrm{CeO}_{2}\right)$ in minor proportions (2 wt\%) has been used to stablish comparisons in performance between natural and synthetic iron oxides. It has been investigated the effect of the reduction temperature, the proportion of methane to carbon dioxide in the feed $\left(\mathrm{CH}_{4}: \mathrm{CO}_{2}\right.$ ratio) and the number of repetitive redox cycles.
\end{abstract}

๑ 2016 Hydrogen Energy Publications LLC. Published by Elsevier Ltd. All rights reserved.

\section{Introduction}

Along the last two decades, the use of hydrogen as energy vector has regained interest [1,2]. Its consumption in the transport sector by means of fuel cells constitutes an emission free alternative versus conventional internal combustion engines powered by fossil fuels. Moreover, hydrogen combustion only produces steam. Since this sector represents almost 19\% of the energy consumption [3] and $30 \%$ of $\mathrm{CO}_{2}$ total emissions worldwide [1], this application would make a significant contribution to brake the anthropogenic greenhouse gas

\footnotetext{
* Corresponding author. Fax: +34 976762043.

E-mail address: jap@unizar.es (J.A. Peña).
} 
emissions trend. However, current hydrogen production methods rely basically on fossil fuels like natural gas by steam reforming. In addition, the demand of high purity hydrogen for polyelectrolyte fuel cells feeding (PEMFC) is only possible at the expense of purification processes like the pressure swing adsorption (PSA) which increases the effective costs per kilogram of hydrogen (PEMFC quality) [4].

In this context, it is proposed a process born in the first decades of the 20th century: the steam-iron process (SIP) [5]. It was employed to produce hydrogen for aeronautical applications. This process is based on the ability of certain metal oxides to be reduced and oxidized (redox properties) in presence of gaseous species and it is conceptually connected to the chemical looping combustion (CLC) [6]. In a first stage, the metal oxide is reduced, preferably to its minimum oxidation state, by presence of reductive gaseous species, to be subsequently reoxidized with steam releasing hydrogen easily separable by condensation of unreacted water. Iron oxide is also recovered in this last stage giving SIP a remarked cyclic character. Iron oxides have been widely used for this application because of its high availability, low cost, and relatively high oxygen carrier capability [7].

Respecting the gaseous species needed to complete the reduction stage of SIP, any feedstock containing a reducing agent might, in principle, be employed [8]. With this aim, biooils or its fractions, like alcoholic, acidic or aldehydic, to name the most representatives, have been tested with promising results [8]. Also biogas has been employed for such purpose given its renewable nature and its significant reductive behavior. Biogas is obtained from the anaerobic fermentation of organic matter, and its use may be specially attractive in regions with high livestock settlement or near to large urban areas where these types of wastes (cattle manure of urban solid wastes) constitute a disposal problem but imply also an intrinsic solution by concentration and reduction of transport costs [9].

As novelty in this work, and focusing in the solid, natural iron ores have been used as oxygen carriers. These are mainly composed of $\mathrm{Fe}_{2} \mathrm{O}_{3}$ (ca. $81 \mathrm{wt} \%$ ) and several other oxides in minor proportions. The use of these oxides, as well as other waste materials (e.g. from steel industry), can be contemplated as a cheaper alternative compared to that of synthetic iron oxides $[10,11]$. However, the presence of various natural impurities such as $\mathrm{SiO}_{2}, \mathrm{Al}_{2} \mathrm{O}_{3}$, or $\mathrm{CaO}$, causes a decrease in reaction rates compared to that of pure materials [12], increasing though its thermal resistance along cycles. For such purpose, the performance of these natural ores have been compared with the results obtained for the same reactions with an iron oxide synthesized in laboratory in which other additives $\left(\mathrm{Al}_{2} \mathrm{O}_{3}\right.$ and $\left.\mathrm{CeO}_{2}\right)$ were included in minor quantities. This "tailored" iron oxide known as "triple oxide" has been the one with the best performance (i.e. thermal stability and reaction rate) explored by this research group to date $[13,14]$.

Another advantage for employing these materials is that their original chemical properties are not affected by the process. So, it is possible to re-use the exhausted solid in their usual application. Currently the main use of these natural oxides is to produce pigments, paints, fertilizers, steels and animal feeding among others.
Given the main constituents of biogas $\left(\mathrm{CH}_{4}\right.$ and $\left.\mathrm{CO}_{2}\right)$, methane dry reforming (MDR) is the main reaction that can be expected to take place along the reduction step. However, due to the poor catalytic activity of the natural iron oxide [15], it has been required the addition of a nickel aluminate with $10 \mathrm{wt} \%$ of nickel oxide in excess above the stoichiometric composition as catalyst. It was synthesized in laboratory [14]. Its good behavior catalyzing dry reforming of methane was demonstrated for reductive feedstocks like sweetened biogas [13], or the decomposition of different fractions of bio-oils [16].

\section{Experimental}

\section{Materials}

A natural iron ore with commercial name "Superfine" was supplied by PROMINDSA (Tierga, Spain), being hematite its main constituent (see Table 1). The only pre-treatment that it received consisted of its calcination at $800^{\circ} \mathrm{C}$ for $8 \mathrm{~h}$ in order to remove carbonate compounds. Fig. 1 shows difractograms comparing samples of raw and calcined iron ore. This last, confirms the absence of $\mathrm{FeCO}_{3}$. On the other hand, the labmade catalyst consisted of $\mathrm{NiAl}_{2} \mathrm{O}_{4}$ with $\mathrm{NiO}$ in excess (10 wt $\%)$ above the stoichiometric spinel structure. It was synthesized by a co-precipitation method at increasing $\mathrm{pH}$ [17]. The synthesis method essentially consisted in preparing aluminum nitrate and nickel nitrate solutions (Sigma Aldrich $99.5 \mathrm{wt} \%), 0.631 \mathrm{M}$ and $1 \mathrm{M}$ respectively from reagents and deionized water. Once they are mixed, an aqueous solution of $\mathrm{NH}_{4} \mathrm{OH} 1 / 10$ at $30 \mathrm{wt} \%$ is gradually poured into the mix at $45^{\circ} \mathrm{C}$ with stirring until pH 7.8-7.9 is achieved. Then it is filtered, washed and dried overnight at $100^{\circ} \mathrm{C}$. Finally, it is calcined at $900{ }^{\circ} \mathrm{C}$ for $3 \mathrm{~h}$. All solids were sieved up to a particle size ranging from 100 to $200 \mu \mathrm{m}$.

\section{Experimental setup}

The experimental system consists of a quartz cylindrical fixed bed reactor $\left(\varnothing_{\mathrm{i}}=0.013 \mathrm{~m}\right)$ inserted in an electric oven $(10 \mathrm{~kW})$. The bed of solids was composed of catalyst (7.5 wt\%), iron ore (67.5 wt\%) and silicon carbide (25 wt\%). SiC was added in order

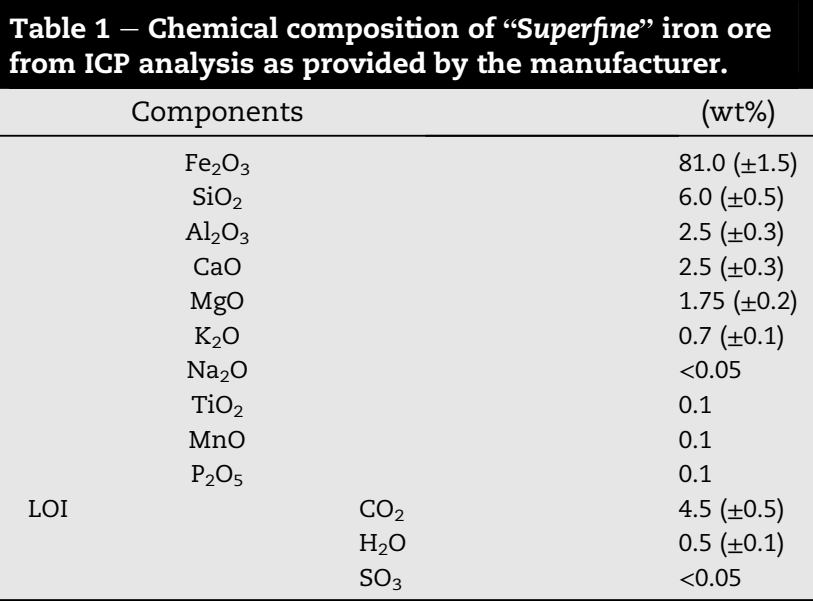




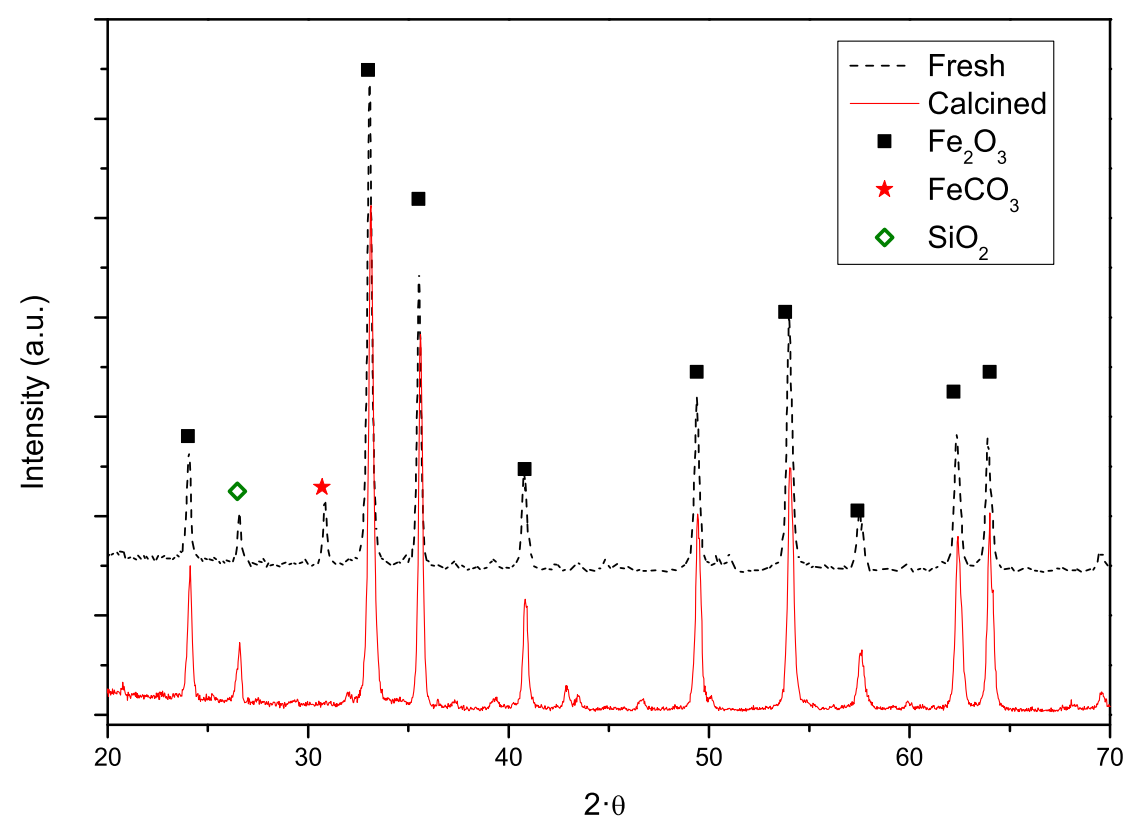

Fig. 1 - - XRD of samples of iron ore fresh and calcined at $800{ }^{\circ} \mathrm{C}$.

to minimize possible temperature profiles along the bed, as well as to prevent agglomeration and preferential channels.

Tests were carried out at atmospheric pressure. The total flow was $250 \mathrm{~mL}$ (STP)/min in both the reduction and the oxidation steps. In the reduction step, the gas stream fed to the reactor contained a synthetic sweetened biogas with a partial pressure of 0.25 bar of reactive gases $\left(\mathrm{CH}_{4}+\mathrm{CO}_{2}\right)$. Different $\mathrm{CH}_{4}: \mathrm{CO}_{2}$ molar ratios (1, 2/3 and 3/7) simulated three different compositions of biogas. Argon was used as internal standard accounting for 0.05 bar of partial pressure. Helium completed the balance. A range of temperatures between 650 and $850{ }^{\circ} \mathrm{C}$ were employed along reductions. Oxidations were always performed at $500^{\circ} \mathrm{C}$, feeding 0.2 bar of steam and He to balance (to atmospheric pressure). The analysis of exhaust gases was performed by means of a gas chromatograph (TCD) Agilent 7890A equipped with HP-Plot/Q and HP-Molesieve columns.

\section{Results and discussion}

\section{Reference experiment}

Based on literature [18] and on a previous work of our group [13], a reference experiment was performed making use of a molar ratio $\mathrm{CH}_{4}: \mathrm{CO}_{2}=1$ and same conditions than those stated in the previous chapter. Bed of solids was constituted by $2.5 \mathrm{~g}$ of a composition as the one described above (catalyst $7.5 \mathrm{wt} \%$, iron ore $67.5 \mathrm{wt} \%$ and SiC $25 \mathrm{wt} \%)$. The temperature chosen for reductions in the reference experiment was $750{ }^{\circ} \mathrm{C}$ and $500^{\circ} \mathrm{C}$ for oxidations.

Fig. 2 shows the distribution of molar flows for several species along reduction stage at the reactor exit. As it has been described for other reactive systems related to solids with REDOX properties $[13,16,19,20]$, this stage can be divided into three consecutive sub-stages, labelled as A, B and C, depending on the main reactions that are taking place.
Along sub-stage "A", methane reduces nickel oxide to metallic nickel present in catalyst particles of $\mathrm{NiAl}_{2} \mathrm{O}_{4}$ with $\mathrm{NiO}$ above its stoichiometric composition (r.1). Simultaneously, hematite $\left(\mathrm{Fe}_{2} \mathrm{O}_{3}\right)$ is reduced to magnetite following the proportions described in reaction (r.2). Emerging metallic $\mathrm{Ni}$ acts as active species, catalyzing the methane dry reforming reaction (r.3) along the whole reduction stage. Along this sub-stage, $\mathrm{CO}_{2}$ and $\mathrm{H}_{2} \mathrm{O}$ molar flows as well as $\mathrm{H}_{2}$ and $\mathrm{CO}$, are almost overlapped.

In sub-stage "B", the gas flow, composed mainly of $\mathrm{H}_{2}$ and $\mathrm{CO}$ (see Fig. 2), allows the reduction of magnetite to iron (r.4) and (r.5) respectively. This sub-stage is marked by a period of time in which the molar flows are almost constant, due to the limitation imposed by the equilibrium between the reducing species generated from (r.3) (i.e. $\mathrm{H}_{2}$ and $\mathrm{CO}$ ), and the presence of $\mathrm{H}_{2} \mathrm{O}$ and $\mathrm{CO}_{2}$ generated from the solid reduction (r.4) and (r.5). Finally, when the reduction of the solid is complete, begins sub-stage "C". This is mainly influenced by the WaterGas-Shift equilibrium (r.6). Sub-stage "C" is not of interest for producing purified $\mathrm{H}_{2}$, but its performance is represented in Fig. 2 in order to give more insight respecting the behavior of gaseous and solid species along reduction.

$$
\begin{aligned}
& 4 \mathrm{NiO}+\mathrm{CH}_{4} \rightarrow 4 \mathrm{Ni}+2 \mathrm{H}_{2} \mathrm{O}+\mathrm{CO}_{2} \\
& 12 \mathrm{Fe}_{2} \mathrm{O}_{3}+\mathrm{CH}_{4} \rightarrow 8 \mathrm{Fe}_{3} \mathrm{O}_{4}+\mathrm{CO}_{2}+2 \mathrm{H}_{2} \mathrm{O} \\
& \mathrm{CH}_{4}+\mathrm{CO}_{2} \rightarrow 2 \mathrm{H}_{2}+2 \mathrm{CO} \\
& \mathrm{Fe}_{3} \mathrm{O}_{4}+4 \mathrm{H}_{2} \rightleftarrows 3 \mathrm{Fe}+4 \mathrm{H}_{2} \mathrm{O} \\
& \mathrm{Fe}_{3} \mathrm{O}_{4}+4 \mathrm{CO} \rightleftarrows 3 \mathrm{Fe}+4 \mathrm{CO}_{2} \\
& \mathrm{H}_{2} \mathrm{O}+\mathrm{CO} \rightleftarrows \mathrm{H}_{2}+\mathrm{CO}_{2}
\end{aligned}
$$




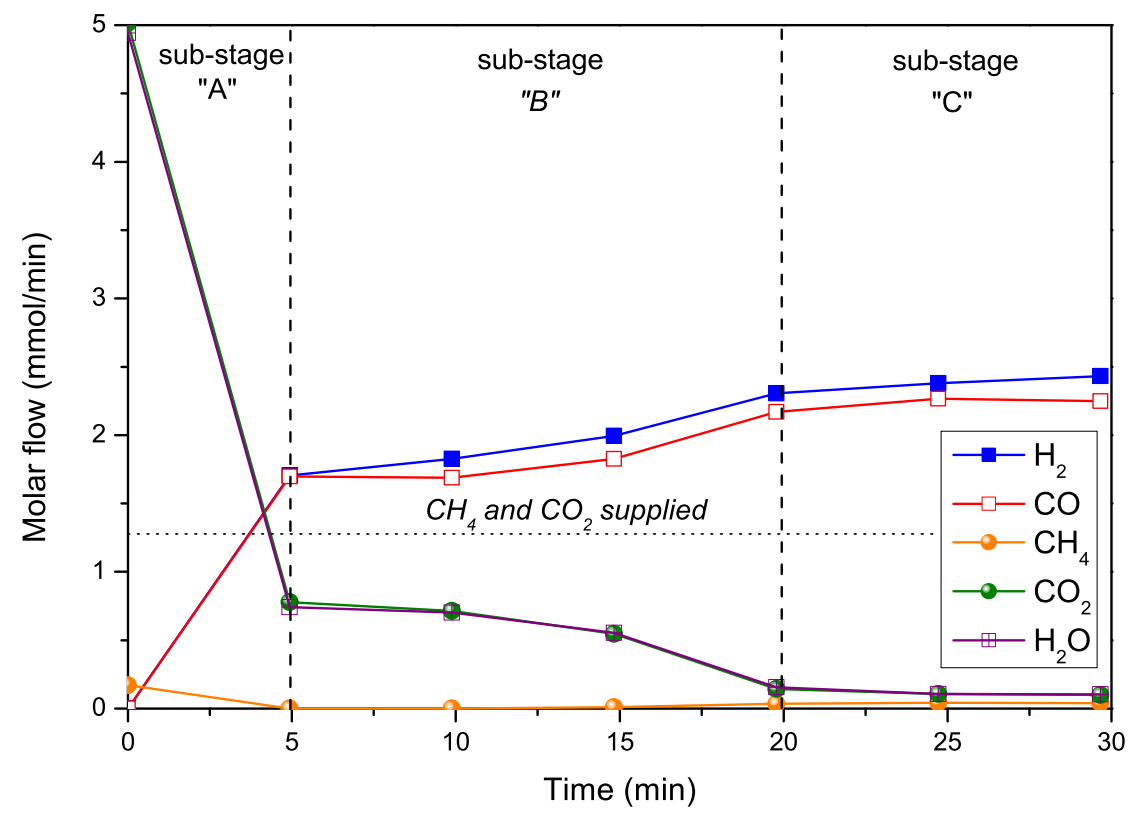

Fig. 2 - Molar flows at the exit of reactor corresponding to the reduction step at $750{ }^{\circ} \mathrm{C}$. Feed consisted of an equimolar mixture $\mathrm{CH}_{4}: \mathrm{CO}_{2}(12.5: 12.5 \mathrm{v} \%)$ diluted in He and $\mathrm{Ar}(5 \mathrm{v} \%)$ as internal standard. Dotted lines represent equimolar flows of $\mathrm{CH}_{4}$ and $\mathrm{CO}_{2}$ fed to reactor.

In addition to the list of reactions described above, some other may also take place like methane steam reforming or its reversal (i.e. methanation reaction) (r.7) and/or the Boudouard reaction (r.8).

$\mathrm{CH}_{4}+\mathrm{H}_{2} \mathrm{O} \rightleftarrows 3 \mathrm{H}_{2}+\mathrm{CO}$

$2 \mathrm{CO} \rightleftarrows \mathrm{C}(\mathrm{s})+\mathrm{CO}_{2}$

Once the solid has been completely reduced along the reduction stage (sub-stages " $\mathrm{A}$ " and "B"), and after a short inertization (around $30 \mathrm{~min}$ with $\mathrm{He}$ ), it proceeds to the oxidation stage. This last is performed supplying $250 \mathrm{~mL}$ (STP)/ min composed of $20 \mathrm{v} \%$ of steam diluted in He. Reaction takes place at $500{ }^{\circ} \mathrm{C}$. Fig. 3 shows the distribution of $\mathrm{H}_{2}$ (gaseous product) and $\mathrm{H}_{2} \mathrm{O}$ (oxidative species) coming from reverse (r.4) along the oxidation stage. The set of operating conditions was based on previous experiments of our group [13]. According to these, at this temperature and proportion of reactive species, the oxidation of iron is possible without gasifying eventual carbonaceous deposits formed (e.g. by Boudouard reaction (r.8)) in the previous reduction stage. On this way, the absence of carbonaceous species in the effluent gases (detection limit $<50$ ppm CO), guarantees the high purity of hydrogen produced along the oxidation stage.

\section{Effect of temperature in the reduction stage}

Reduction stage was performed at temperatures ranging from $650^{\circ} \mathrm{C}$ to $850^{\circ} \mathrm{C}$, maintaining the same composition of gases in the feed and the same loading of solids in the packed bed, as the one in the reference experiment described previously.

Fig. 4 shows the $\mathrm{CO}$ ratio (Eq. (1)) at the exit of the reactor, along the iron ore reduction stage at several temperatures.
Same sub-stages as those described in Fig. 2 can be noted here. In general, the higher the temperature, the lower the time required to complete the reduction of the solid bed. Reasons must be found in the major presence of reducing species $\left(\mathrm{H}_{2}\right.$ and $\mathrm{CO}$ ) versus oxidizing ones $\left(\mathrm{H}_{2} \mathrm{O}\right.$ and $\left.\mathrm{CO}_{2}\right)$ probably motivated by the prevailing role of methane dry reforming reaction (r.3) instead of the reduction of iron ore ((r.4) and (r.5)). This fact is well noticed at $850{ }^{\circ} \mathrm{C}$, the higher temperature employed in this study. On the contrary, the experiment performed at $650{ }^{\circ} \mathrm{C}$ (i.e. lower temperature employed) is far away from achieving the sub-stage "C" in $30 \mathrm{~min}$. Summarizing, the effect of increasing temperature results in a higher $\mathrm{CO}$ ratio along sub-stage " $\mathrm{A}$ ", the shortening in time of substage "B", and finally stable values of CO ratio well identifiable with the theoretical ones predicted by the Boudouard equilibrium (r.8). In addition, in the case of $650{ }^{\circ} \mathrm{C}$, it was observed the increment of the system overpressure due to the significant deposition of coke inside the reactor. This implies an important operational problem to take into account in an eventual industrial use, since that can lead to the clogging of the bed after a high number of cycles.

CO ratio $=\frac{\text { molar flow of } \mathrm{CO}}{\text { molar flow of } \mathrm{CO}+\text { molar flow of } \mathrm{CO}_{2}}$

Coke deposition decreases as higher is the reduction temperature. It has been measured estimating the unbalance of carbon between inlet (fixed feed flow) and outlet stream (i.e. measured by concentration of carbonaceous species by GC) at different reduction temperatures. Results show that with a bed of solids of $2.5 \mathrm{~g}$, as described in the experimental section of this work, the mass of coke formed at the end of sub-stage " $\mathrm{B}$ " is as low as $98 \mathrm{mg}\left(650^{\circ} \mathrm{C}\right), 34 \mathrm{mg}\left(750^{\circ} \mathrm{C}\right)$ and $3 \mathrm{mg}\left(850^{\circ} \mathrm{C}\right)$ respectively. 


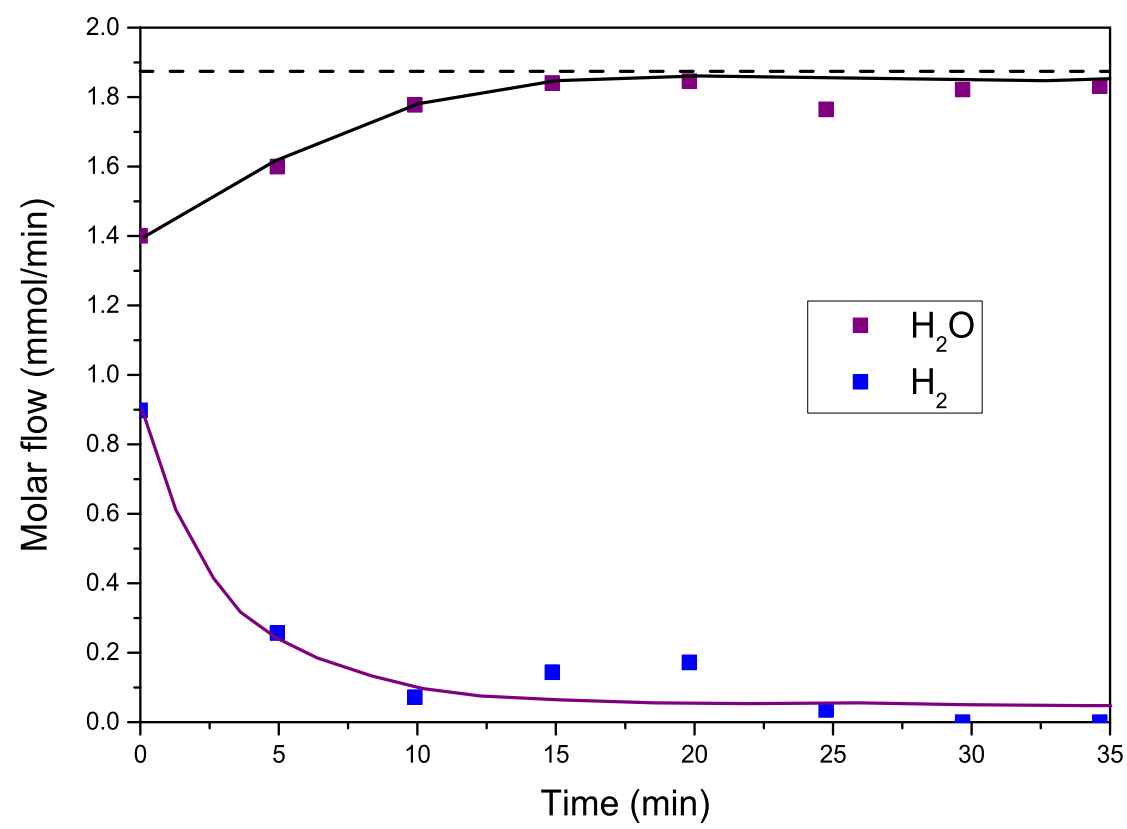

Fig. 3 - Molar flows at the exit of reactor along the oxidation step in a reference experiment $\left(\mathrm{T}_{\text {oxidation }}=500{ }^{\circ} \mathrm{C}\right.$, previous reduction $\mathrm{T}_{\text {reduction }}=750^{\circ} \mathrm{C}$, Feed: equimolar mixture of $\mathrm{CH}_{4}$ and $\mathrm{CO}_{2}$ ). Dashed line represents the molar flowrate of steam fed.

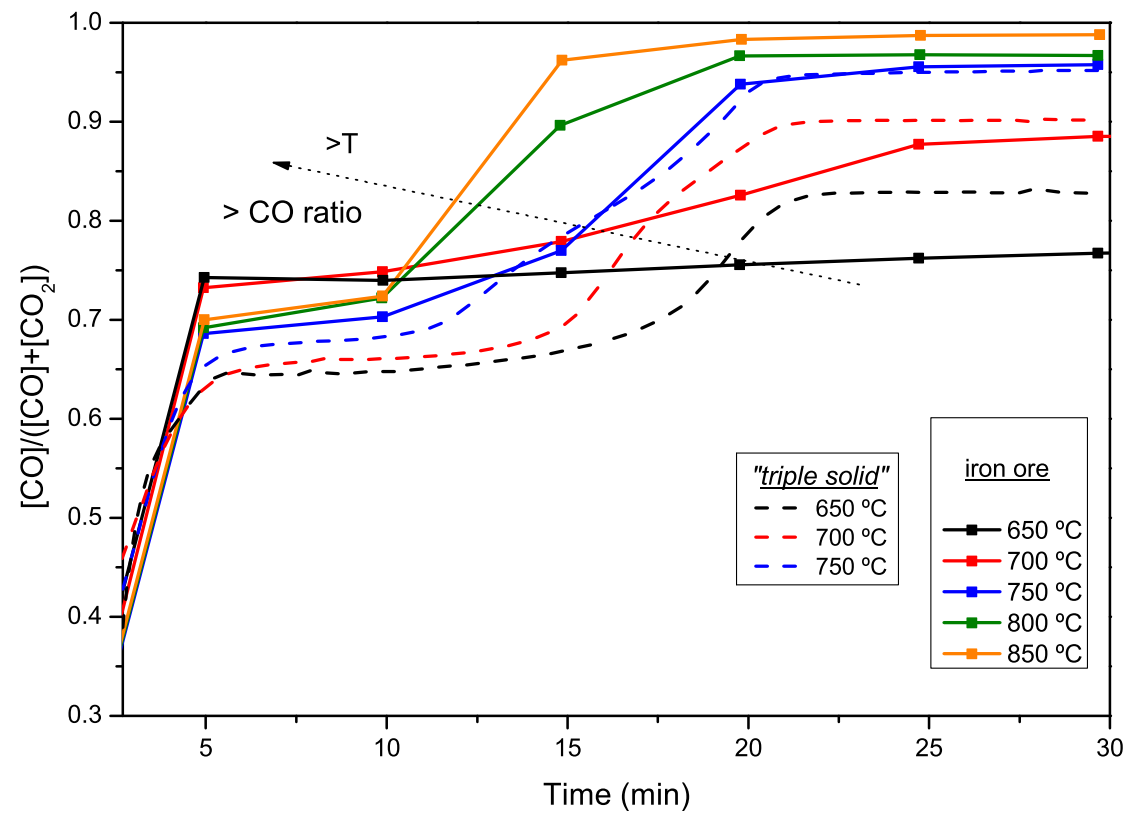

Fig. 4 - CO ratio (Eq. (1)) at different reduction temperatures along the first reduction stage for iron ore and "triple oxide" [13] for comparison purposes.

For the sake of comparison, dashed lines show the results obtained with an iron oxide (labelled as "triple oxide") synthesized in our lab, which included, in addition to hematite, small amounts of alumina (1.75 wt\%) and ceria (0.25 wt\%) [13]. More details about the synthesis process (citrates), and the optimization of its composition for a good activity and stability can be found in literature [21,22]. The effect of these additives is that alumina improves the thermal stability of the iron oxide $[23,24]$, while ceria improves the lattice oxygen transfer rate, both in reductions and oxidations [25]. As it can be noticed from Fig. 4, although the reducible oxide content in the iron ore (i.e. $81 \mathrm{wt} \%$ corresponding to hematite), is much lower than in the "triple oxide" (98 wt\%), the first needs more time to be reduced at lower temperatures $\left(650^{\circ} \mathrm{C}\right.$ and $\left.700{ }^{\circ} \mathrm{C}\right)$ or almost the same at the higher of those used for comparison $\left(750^{\circ} \mathrm{C}\right)$. It is known that the main reason for such delay is the effect of the natural impurities present in the ore, $\mathrm{Al}_{2} \mathrm{O}_{3}$ and $\mathrm{SiO}_{2}$, as well as the absence of $\mathrm{CeO}_{2}$ present in the synthetic one [26]. 


\section{Effect of redox cycles in the reduction stage}

This effect was analyzed carrying out several redox cycles at different reduction temperatures $\left(650-850{ }^{\circ} \mathrm{C}\right)$ with $250 \mathrm{~mL}$ (STP)/min composed of $12.5 \mathrm{v} \% \mathrm{CH}_{4}, 12.5 \mathrm{v} \% \mathrm{CO}_{2}, 5 \mathrm{v} \% \mathrm{Ar}$ and He to balance as feedstock. Respecting the subsequent oxidations, this step was always performed at $500{ }^{\circ} \mathrm{C}$ regardless of the temperature at which reduction was carried out.

Fig. 5 shows the CO ratio (Eq. (1)) observed when a third reduction is carried out after two consecutive redox cycles (i.e. cycle $=$ reduction stage + oxidation stage) at two different temperatures $700^{\circ} \mathrm{C}$ and $750^{\circ} \mathrm{C}$ (always $500^{\circ} \mathrm{C}$ for oxidations). Also for comparison purposes (dashed lines), it is shown the CO ratio for "triple oxide" used as oxygen carrier at the same temperatures [13]. Iron ore, unlike "triple oxide", exhibits a greater decrease in the time to reach its sub-stage "C" (see Fig. 2 as reference). What can be ascribed at first sight as a greater rate for reduction of the iron ore, is actually masking the significant loss of the mass of reducible solid due to sintering. The plateau observed for both solids and different temperatures is motivated by the equilibrium imposed by the Boudouard reaction (r.8). This issue will be revisited later on.

\section{Effect of redox cycles on the hydrogen produced in oxidation stage}

To quantify hydrogen yields along the steam-iron process from both, ore and synthetic biogas standpoint, two indexes have been defined as (Eq. (2)) and (Eq. (3)) respectively. First one (Eq. (2)) accounts for the mass of hydrogen released from the reactor (oxidation stage) upon $100 \mathrm{~g}$ of reactive solid (iron ore or "triple oxide") present in the fixed bed providing an idea about the effectiveness of the solid as redox actor in the process. The second one (Eq. (3)) does it from the point of view of the raw material, accounting for the mass of hydrogen released (also oxidation stage) from $100 \mathrm{~g}$ of hydrogen in the synthetic biogas processed. This last gives an idea about the effectiveness of hydrogen production from biogas in the process.

$$
\begin{aligned}
& Y_{\mathrm{H}_{2}}^{\text {ore }}=\frac{g \mathrm{H}_{2} \text { at reactor exit }}{100 \mathrm{~g} \text { of solid }} \\
& Y_{\mathrm{H}_{2}}^{\text {biogas }}=\frac{g \mathrm{H}_{2} \text { at reactor exit }}{100 \mathrm{~g} \mathrm{H}_{2} \text { in biogas fed }}
\end{aligned}
$$

Fig. 6 shows values of these indexes when the reduction stage has been carried out at $700{ }^{\circ} \mathrm{C}$ and its subsequent oxidation at $500{ }^{\circ} \mathrm{C}$. Iron ore and "triple oxide" were employed as oxygen carriers to underline the differences. The redox cycles were repeated up to four consecutive times. Iron ore shows a much more stable production of hydrogen according to $\mathrm{Y}_{\mathrm{H}_{2}}^{\text {ore }}$ index (Eq. (2)). However, these values are considerably lower than those found for "triple oxide" as consequence of the noticeably low oxidation rates attained with the natural material. Respecting the efficiency in hydrogen separation from biogas, $\mathrm{Y}_{\mathrm{H}_{2}}^{\text {biogas }}$ index (Eq. (3)), iron ore is again penalized because of the intense consumption of reducing agent required for its complete reduction.

Also regarding this issue, the yields of hydrogen have been compared to reported data found in literature [27-29] for systems performing methane dry reforming (MDR) as single process (i.e. not coupled to SIP) at the same reduction temperature, but with different catalysts. Both oxygen carriers used in this work present lower hydrogen performance; however, it is noteworthy that the hydrogen produced in this study, unlike the others, exhibits higher purity (detection limit below $50 \mathrm{ppm} \mathrm{CO}$ ), not requiring an additional purification stage for certain PEMFC applications. Moreover, in the indexes defined by equations (Eq. (2)) and (Eq. (3)) only the hydrogen produced as a result of the oxidation step has been taken into

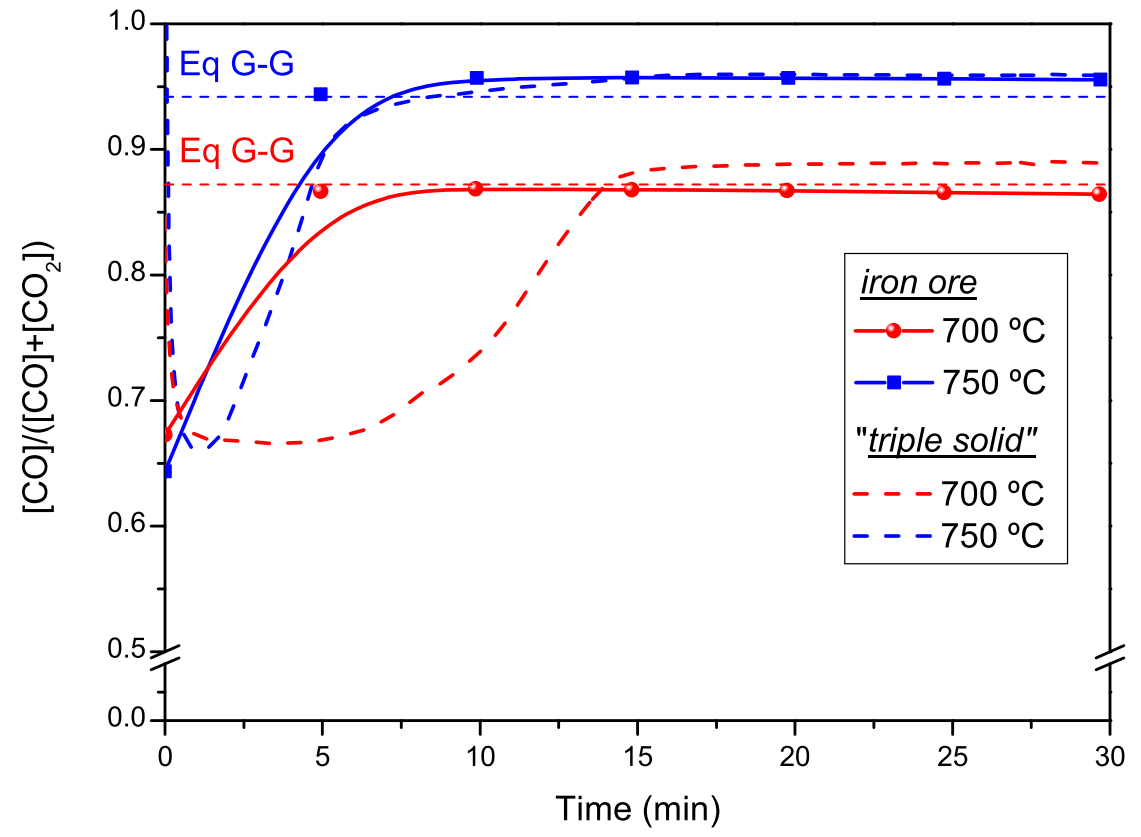

Fig. 5 - CO ratio for iron ore and "triple oxide" at different reduction temperatures along the third consecutive reduction stage. 


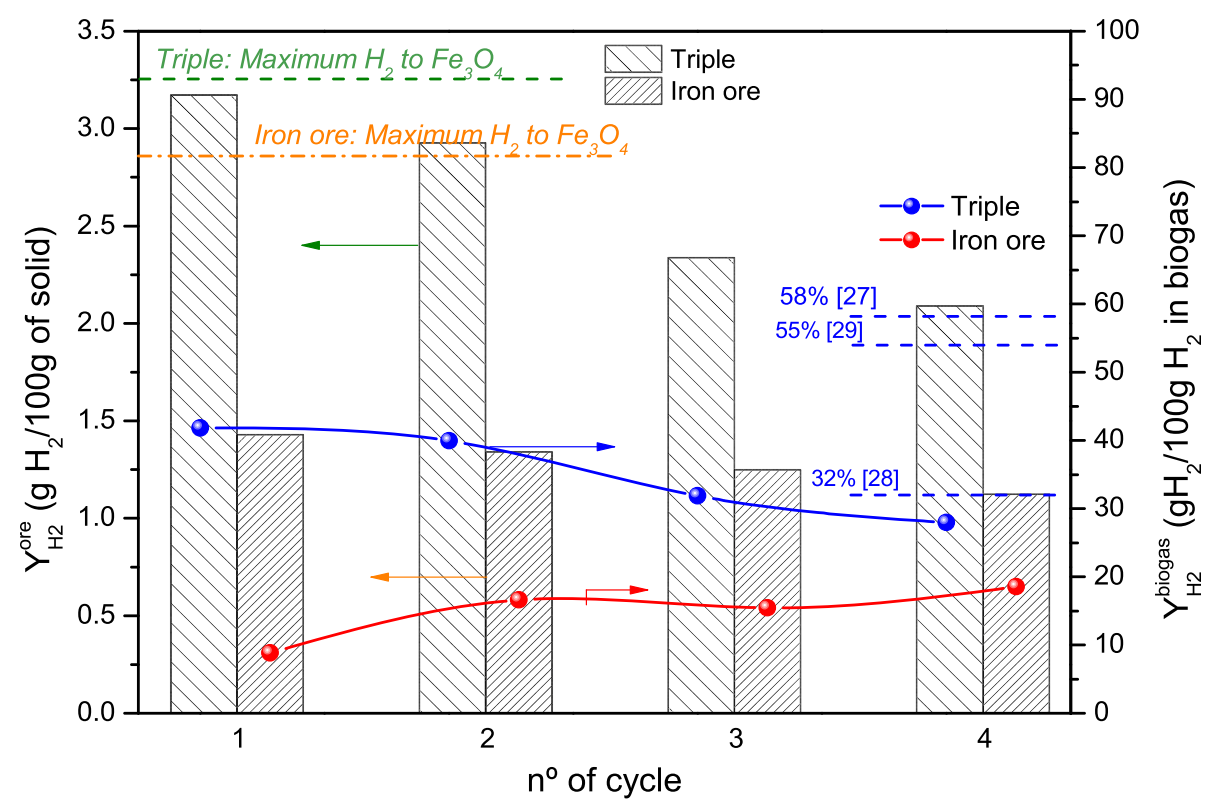

Fig. 6 - - Evolution of hydrogen yields produced in the oxidation stage, based on the amount of solid present in the reactor (Eq. (2)) and the amount of hydrogen present in the processed biogas (Eq. (3)), along up to four consecutive redox cycles. Iron ore and "triple oxide" were used as oxygen carriers. Results from Refs. [27-29] included for comparison.

account. Hydrogen emerging from MDR along the reduction step has not been computed in the numerator of these indexes.

Effect of the variation of the biogas $\mathrm{CH}_{4}: \mathrm{CO}_{2}$ ratio in the reduction stage

Several experiments were carried out maintaining the reduction temperature at $750{ }^{\circ} \mathrm{C}$ and fixing the $\mathrm{CH}_{4}: \mathrm{CO}_{2}$ molar ratio of the feed stream at 1:1, 2:3 and 3:7. The rest of operating variables were maintained as in the reference experiment described above. Mixtures enriched in $\mathrm{CO}_{2}$ at the expense of
$\mathrm{CH}_{4}$ can be representatives of poorer biogases, that might result unattractive for the direct conversion into electricity in an internal combustion engine, due to their poorer heating values and the difficulties derived from the anti-knock properties of such mixtures. Fig. 7 shows the CO ratio (Eq. (1)) of the above mentioned feeds enriched in $\mathrm{CO}_{2}$ along the reduction stage of iron ore. The lower is the $\mathrm{CH}_{4}: \mathrm{CO}_{2}$ molar ratio in the feedstock, the longer is the time needed to reduce the solid according to the lower reductor behavior of the mixture and the limited extent of the methane dry reforming reaction (r.3). Likewise, the transition between sub-stages " $\mathrm{B}$ " and " $\mathrm{C}$ " is clearly affected by the increment of oxidant species in the

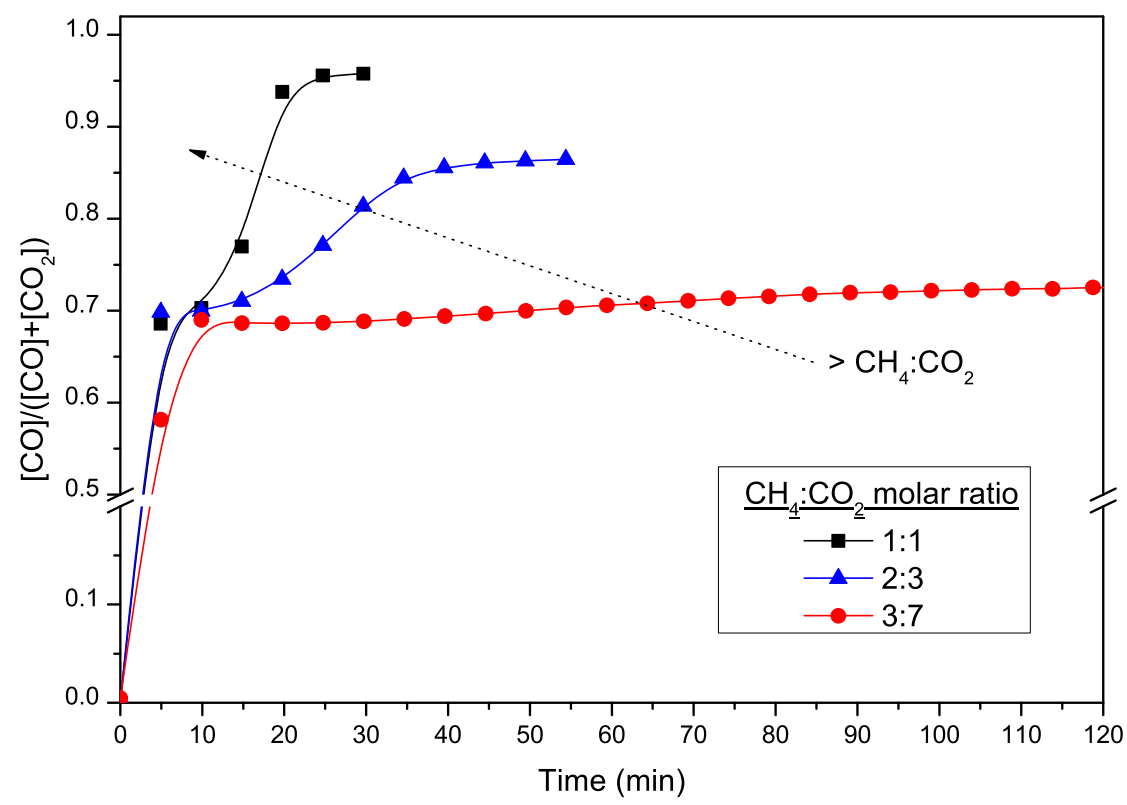

Fig. 7 - - CO ratio obtained with iron ore along the reduction stage with different $\mathrm{CH}_{4}: \mathrm{CO}_{2}$ ratios in the feedstock at $750{ }^{\circ} \mathrm{C}$. 


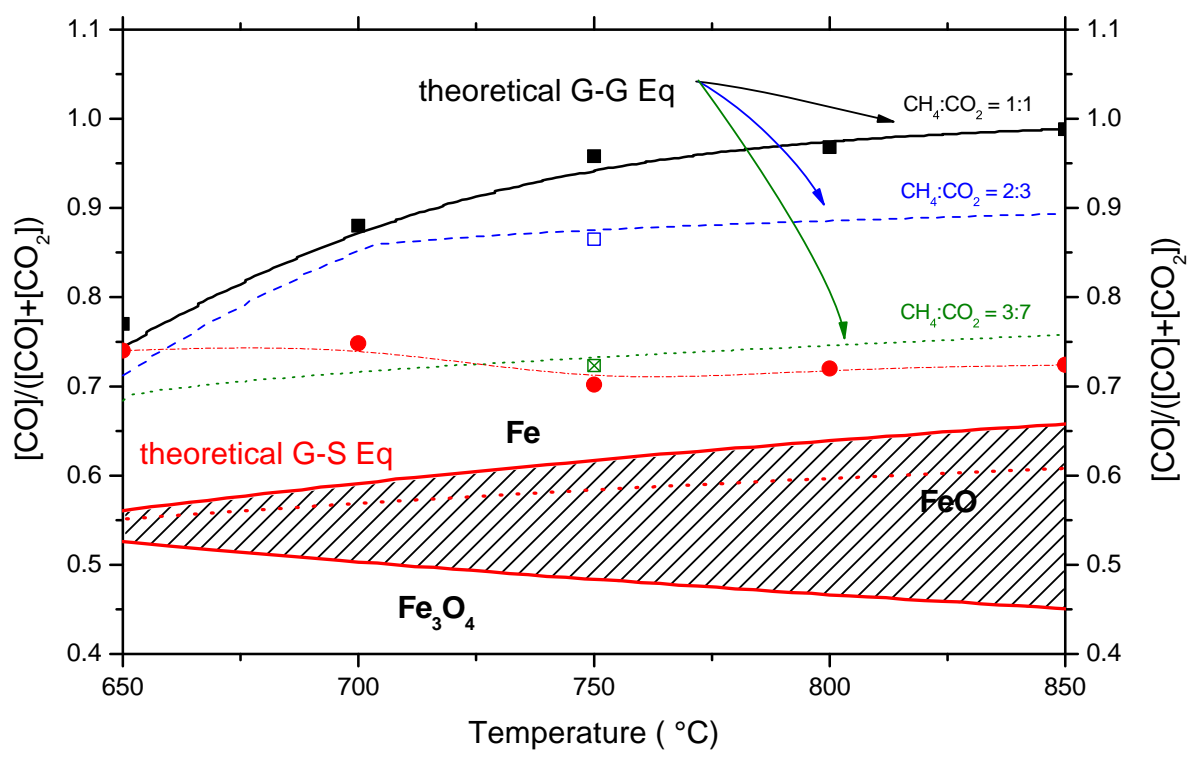

Fig. 8 - - Theoretical G-G and G-S equilibria vs. experimental ones for several temperatures and molar ratios $\mathrm{CH}_{4}: \mathrm{CO}_{2}$ in the feed.

feedstock, being it shortened in mixtures with high $\mathrm{CH}_{4}$ content, and making the transition extremely slow for those with the higher $\mathrm{CO}_{2}$ proportion.

\section{Comparison of experimental results with the theoretical equilibrium}

Fig. 8 represents the $\mathrm{CO}$ ratio (Eq. (1)) at different temperatures and for different $\mathrm{CH}_{4}: \mathrm{CO}_{2}$ feed molar ratios. Sub-stage "C", corresponding to the reduced state of the iron ore (see Fig. 2), is related to the $\mathrm{G}-\mathrm{G}$ equilibrium, as can be evidenced from the comparison between empirical results (symbols) and theoretical curves (lines) calculated by minimization of the Gibbs free energy $\left(\Delta G^{\circ}\right)$ of the different species present at the exit of the reactor.

Squared symbols represent empirical results obtained along sub-stage "C" for each of the feedstocks used in this work $(1,2 / 3,3 / 7)$. Both, theoretical and empirical agree completely.

Same figure includes also the Baur-Glaessner diagram [30] representing equilibria between iron oxides in different oxidation states $\left(\mathrm{Fe}_{3} \mathrm{O}_{4} \rightarrow \mathrm{FeO} \rightarrow \mathrm{Fe}\right)$. Hematite phase $\left(\mathrm{Fe}_{2} \mathrm{O}_{3}\right)$ is not shown for the sake of clarity. The upper curve of the shadowed area represents the theoretical CO ratio (Eq. (1)) according to the equilibrium between reduced iron $(\mathrm{Fe})$ and magnetite $\left(\mathrm{Fe}_{3} \mathrm{O}_{4}\right)$. This theoretical curve should be related to the pseudo-equilibrium described by the sub-stage "B" (see Fig. 2). Experimental results for such sub-stage (circles) keep a certain distance from the theoretical values represented by the red curve above the shadowed area. The gap between theoretical and empirical is almost constant from $750{ }^{\circ} \mathrm{C}$ on. This phenomenon agrees with that previously observed in other comparable systems $[13,16,19,20]$ and it is justified by the existence of diffusional restrictions of reactives and/or product species to achieve the reaction front in the surface of particle along the reduction stage, as it has been described in literature [31,32].

\section{Conclusions}

The present study has analyzed the viability of using natural iron ores as oxygen carriers for the steam-iron process (SIP), using a feed stream with different ratios $\mathrm{CH}_{4}: \mathrm{CO}_{2}$ as reducing agent. These intended to simulate a synthetic sweetened biogas with different compositions. A catalyst has been needed to complete the reduction in all cases. The one selected has been a $\mathrm{NiAl}_{2} \mathrm{O}_{4}$ with excess of $\mathrm{NiO}$ (10 wt\%) above its stoichiometric composition. As it has been observed, the iron ore reduction follows a similar behavior than the one experimented by a solid synthesized in lab (i.e. "triple oxide") which includes small quantities of additives (up to $2 \mathrm{wt} \%$ ). The first sub-stage (sub-stage "A"), consists of the reduction of nickel oxide and hematite into metallic nickel and magnetite respectively by combustion of $\mathrm{CH}_{4}$ with lattice oxygen of the solids. This is followed by a pseudo-equilibrium (molar flow of species almost constant for a period of time) due to the reduction of magnetite into iron. Finally, once iron oxide has been reduced, the distribution of species is mainly influenced by the WGS reaction equilibrium. The subsequent oxidation with steam (always at $500{ }^{\circ} \mathrm{C}$ ) allows producing high purity hydrogen since no carbon compounds $\left(\mathrm{CO}\right.$ or $\left.\mathrm{CO}_{2}\right)$ were observed at the exhaust gases.

The high temperatures $\left(\geq 700^{\circ} \mathrm{C}\right)$ needed to reduce the solid without a significant coke deposition for $\mathrm{CH}_{4}: \mathrm{CO}_{2}$ ratio equal to one, cause sintering in the solid. That induces a decrement in the oxidation rate, and therefore a drop in the amount of reducible solid in the subsequent cycle. The carbonaceous depositions can be diminished employing biogases with $\mathrm{CH}_{4}: \mathrm{CO}_{2}$ ratios lower than one (i.e. poorer heating values); 
however, this would imply a loss of yield due to the increment of the time needed to reduce the solid.

Iron ore has a lower reduction rate as well as lower resistance to sintering than other solids based in iron oxide as is the case of "triple oxide". These features result in a lower $\mathrm{H}_{2}$ production along repetitive cycles. However, the residual production of hydrogen for iron ore is more stable than that when the hydrogen is obtained with "triple oxide" along four consecutive redox cycles. Its low hydrogen yield could be compensated too by the reduced cost of iron oxide ore and its high availability. In addition, the possibility of employing this natural iron oxide to produce hydrogen by steam-iron represents an added value for this natural oxide, since once exhausted, the iron ore could be recycled into its traditional applications (e.g. pigments and dyes). Besides, in spite of the low hydrogen yield obtained per cycle, compared to other process of hydrogen production by MDR, this hydrogen has high purity, so a subsequent purification stage is not required.

\section{Acknowledgements}

Financial support for this work has been provided by the Spanish Ministerio de Economía y Competitividad (MINECO), through project ENE2013-44350-R. J. Lachén also thanks the same institution for the grant BES-2014-067984. Financial aid for the maintenance of the consolidated research group CREG has been provided by the Fondo Social Europeo through the Gobierno de Aragón (Aragón, Spain).

\section{R E F E R E N C E S}

[1] Hosseini SE, Wahid MA. Hydrogen production from renewable and sustainable energy resources: promising green energy carrier for clean development. Renew Sustain Energy Rev 2016;57:850-66. http://dx.doi.org/10.1016/ j.rser.2015.12.112.

[2] Ball M, Weeda M. The hydrogen economy - vision or reality? Int J Hydrogen Energy 2015;40:7903-19. http://dx.doi.org/ 10.1016/j.ijhydene.2015.04.032.

[3] U.S. Energy Information Administration (EIA). International energy outlook 2016. 2016.

[4] Papadias DD, Ahmed S, Kumar R, Joseck F. Hydrogen quality for fuel cell vehicles - a modeling study of the sensitivity of impurity content in hydrogen to the process variables in the SMR-PSA pathway. Int J Hydrogen Energy 2009;34:6021-35. http://dx.doi.org/10.1016/j.ijhydene.2009.06.026.

[5] Messerschmitt A. Process of producing hydrogen - U.S. Patent No. 971, 206. 971, 206. 1910.

[6] Adanez J, Abad A, Garcia-Labiano F, Gayan P, de Diego LF. Progress in chemical-looping combustion and reforming technologies. Prog Energy Combust Sci 2012;38:215-82. http://dx.doi.org/10.1016/j.pecs.2011.09.001.

[7] Bleeker MF, Veringa HJ, Kersten SRA. Deactivation of iron oxide used in the steam-iron process to produce hydrogen. Appl Catal A Gen 2009;357:5-17. http://dx.doi.org/10.1016/ j.apcata.2008.12.032.

[8] Bleeker MF, Veringa HJ, Kersten SRA. Pure hydrogen production from pyrolysis oil using the steam iron process: effects of temperature and iron oxide conversion in the reduction. Ind Eng Chem Res 2010;49:53-64.
[9] Hijazi O, Munro S, Zerhusen B, Effenberger M. Review of life cycle assessment for biogas production in Europe. Renew Sustain Energy Rev 2016;54:1291-300. http://dx.doi.org/ 10.1016/j.rser.2015.10.013.

[10] Hui W, Takenaka S, Otsuka K. Hydrogen storage properties of modified fumed-Fe-dust generated from a revolving furnace at a steel industry. Int J Hydrogen Energy 2006;31:1732-46. http://dx.doi.org/10.1016/j.ijhydene.2005.12.010.

[11] Haider SK, Azimi G, Duan L, Anthony EJ, Patchigolla K, Oakey JE, et al. Enhancing properties of iron and manganese ores as oxygen carriers for chemical looping processes by dry impregnation. Appl Energy 2016;163:41-50. http://dx.doi.org/ 10.1016/j.apenergy.2015.10.142.

[12] Ettabirou M, Dupré B, Gleitzer C. Nucleation and early growth of magnetite on synthetic and natural hematite crystals. React Solids 1986;1:329-43. http://dx.doi.org/10.1016/01687336(86)80025-0.

[13] Herrer M, Plou J, Durán P, Herguido J, Peña JA. Hydrogen from synthetic biogas via SIP using $\mathrm{NiAl}_{2} \mathrm{O}_{4}$ catalyst: reduction stage. Int J Hydrogen Energy 2015;40:5244-50. http:// dx.doi.org/10.1016/j.ijhydene.2015.01.063.

[14] Plou J, Durán P, Herguido J, Peña JA. Hydrogen from synthetic biogas by catalyzed MDR and SIP: screening of catalyst and iron oxide mixtures. Fuel 2015;140:470-6. http://dx.doi.org/ 10.1016/j.fuel.2014.09.116.

[15] Plou J, Duran P, Herguido J, Peña JA. Purified hydrogen from synthetic biogas by joint methane dry reforming and steamiron process: behaviour of metallic oxides and coke formation. Fuel 2014;118:100-6. http://dx.doi.org/10.1016/ j.fuel.2013.10.069.

[16] Lachen J, Plou J, Durán P, Herguido J, Peña JA. High-purity hydrogen from acidic fractions of bio-oil by "steam-iron." Eur. Hydrog. Energy Conf. (EHEC 2014). Seville (Spain): Spanish Hydrogen Association; 2014. p. 595-8.

[17] Al-Ubaid A, Wolf EE. Steam reforming of methane on reduced non-stoichiometric nickel aluminate catalysts. Appl Catal 1988;40:73-85. http://dx.doi.org/10.1016/S0166-9834(00) 80427-3.

[18] Deublein D, Steinhauser A. Biogas from waste and renewable resources. An introduction. Wiley VCH; 2008.

[19] Hormilleja E, Durán P, Plou J, Herguido J, Peña JA. Hydrogen from ethanol by steam iron process in fixed bed reactor. Int $J$ Hydrogen Energy 2014;39:5267-73. http://dx.doi.org/10.1016/ j.ijhydene.2014.01.002.

[20] Campo R, Durán P, Plou J, Herguido J, Peña JA. Combined production and purification of hydrogen from methanol using steam iron process in fixed bed reactor. J Power Sour 2013;242:520-6.

[21] Kirchnerova J, Alifanti M, Delmon B. Evidence of phase cooperation in the $\mathrm{LaCoO}_{3}-\mathrm{CeO}_{2}-\mathrm{Co}_{3} \mathrm{O}_{4}$ catalytic system in relation to activity in methane combustion. Appl Catal A Gen 2002;231:65-80. http://dx.doi.org/10.1016/S0926-860X(01) 00903-6.

[22] Peña JA, Palacios A, Martínez L, Romero E, Durán P, Herguido J. Effect of impurities of the solid on the subsequent hydrogen release in steam- iron process. In: Stolten D, Grube T, editors. 18th World Hydrog. Energy Conf. 2010-WHEC 2010vol. Parallel S. Essen (Germany): Forschungszentrum Jülich GmbH, Zentralbibliothek, Verlag; 2010. p. 379.

[23] Otsuka K, Yamada C, Kaburagi T, Takenaka S. Hydrogen storage and production by redox of iron oxide for polymer electrolyte fuel cell vehicles. Int J Hydrogen Energy 2003;28:335-42. http://dx.doi.org/10.1016/S0360-3199(02) 00070-8.

[24] Otsuka K, Kaburagi T, Yamada C, Takenaka S. Chemical storage of hydrogen by modified iron oxides. J Power Sour 2003;122:111-21. http://dx.doi.org/10.1016/S0378-7753(03) 00398-7. 
[25] Konsolakis M, Sgourakis M, Carabineiro SAC. Surface and redox properties of cobalt-ceria binary oxides: on the effect of Co content and pretreatment conditions. Appl Surf Sci 2015;341:48-54. http://dx.doi.org/10.1016/ j.apsusc.2015.02.188.

[26] Lorente E, Peña JA, Herguido J. Cycle behaviour of iron ores in the steam-iron process. Int J Hydrogen Energy 2011;36:7043-50. http://dx.doi.org/10.1016/ j.ijhydene.2011.03.069.

[27] Steinhauer B, Kasireddy MR, Radnik J, Martin A. Development of Ni-Pd bimetallic catalysts for the utilization of carbon dioxide and methane by dry reforming. Appl Catal A Gen 2009;366:333-41. http://dx.doi.org/10.1016/ j.apcata.2009.07.021.

[28] Kambolis A, Matralis H, Trovarelli A, Papadopoulou C. Ni/ $\mathrm{CeO} 2-\mathrm{ZrO} 2$ catalysts for the dry reforming of methane. Appl
Catal A Gen 2010;377:16-26. http://dx.doi.org/10.1016/ j.apcata.2010.01.013.

[29] Khani Y, Shariatinia Z, Bahadoran F. High catalytic activity and stability of ZnLaAlO4 supported $\mathrm{Ni}, \mathrm{Pt}$ and Ru nanocatalysts applied in the dry, steam and combined drysteam reforming of methane. Chem Eng J 2016;299:353-66. http://dx.doi.org/10.1016/j.cej.2016.04.108.

[30] Baur E, Glaessner A. Equilibrium between iron oxides and carbon monoxide and carbon dioxide. J Chem Soc 1903;84:423.

[31] Pineau A, Kanari N, Gaballah I. Kinetics of reduction of iron oxides by H2. Thermochim Acta 2007;456:75-88. http:// dx.doi.org/10.1016/j.tca.2007.01.014.

[32] Tokuda M, Yoshikoshi H, Ohtani M. Kinetics of the reduction of Fe ore. Trans Iron Steel Inst Jpn 1973;13:350-63. 